\title{
The Impact of a Personalized Preventive Care Model vs. the Conventional Healthcare Model on Patient Satisfaction
}

\author{
Andrea Klemes ${ }^{1, *}$ and Harold Solomon ${ }^{2}$ \\ ${ }^{I}$ MDVIP, Boca Raton, Florida, USA ${ }^{2}$ MDVIP-affiliated practice physician, Boston, Massachusetts, USA
}

\begin{abstract}
Introduction: The ability of physicians to achieve successful outcomes for their patients is a challenge given the increasing demands on physicians in the conventional healthcare world. Patients are becoming more involved with their healthcare management and, as such, their satisfaction with their physician is increasingly important. MD-Value in Prevention (MDVIP) is a network of primary care physicians who promote smaller practice sizes in an effort to allow the physician to focus on prevention, wellness and chronic issues. Methods: An online patient satisfaction survey with MDVIP members and a representative population of patients in the conventional healthcare system (CHC) was conducted. Results: MDVIP members were significantly more satisfied with their ability to reach their physician when needed, including their ability to contact their physician during business hours (90-91\% of MDVIP patients versus 53\% of CHC patients) and contact their physician after business hours (71-74\% of MDVIP patients versus $31 \%$ of CHC patients), $\mathrm{p}<0.05$ for both parameters. In addition, $97 \%$ of MDVIP members were satisfied with their relationship with their physician compared to just $58 \%$ of $\mathrm{CHC}$ patients $(\mathrm{p}<0.05)$. Patient-reported physician loyalty was much higher in the MDVIP groups compared to the CHC population (68-72\% in the MDVIP groups versus $44 \%$ in the CHC group, $\mathrm{p}<0.05$ ). Conclusion: The MDVIP model significantly enables a better primary care physician-patient relationship versus the conventional healthcare system, which ultimately may lead to better health outcomes. Patients in the MDVIP model have better access, are more satisfied and more loyal to their physician compared to their CHC counterparts.
\end{abstract}

Keywords: MDVIP, patient satisfaction, personalized care, prevention, primary care.

\section{INTRODUCTION}

At the heart of primary care is the physician-patient relationship in which the knowledge and diagnostic skills of the physician, along with compassion, work for the benefit of the patient. The ability of physicians to achieve successful outcomes for patients is a daily challenge, given the increasing demands on physicians in the conventional healthcare world [1]. The healthcare system is currently structured to provide incentives in the reimbursement structure, often leaving patients' needs as an afterthought [2]. In addition, managed care has perpetuated a fee-for-service system in which additional time involving telephone and email communication with patients and time spent on management and coordination of care are not reimbursable [3]; thus, physicians spend less time on them. Physicians need that time to connect and engage with patients. With ever-increasing healthcare demand and costs, patients have become more involved and more responsible for their own healthcare management.

While in the past patient opinion was considered optional, patient satisfaction with the healthcare they receive is now recognized as an important aspect of quality and essential to achieving high quality care [4]. A nationwide survey of U.S. residents in 2004 conducted by Harvard University, the Agency for Healthcare Research and Quality and the

*Address correspondence to this author at the MDVIP | 1875 NW Corporate Blvd., Ste. 300, Boca Raton, FL 33431, USA; Tel: 561-982-4303;

Fax: 561-455-9215; E-mail: aklemes@mdvip.com
Henry J. Kaiser Family Foundation found that 55\% of respondents were dissatisfied with their healthcare [5]. As noted by Dowd et al, patient satisfaction is a measure of the discrepancy between a patient's expectation regarding an encounter with his or her physician/provider and the patient's actual experience, and these discrepancies can occur with regard to the ease of getting an appointment, waiting time in the office, attentiveness and courtesy, prescribed treatments and health outcomes [6]. Several studies have found a consistent and significant positive association between patient satisfaction and interpersonal continuity of care $[7,8]$.

While healthcare providers recognize that they must provide services that fulfill the needs and wants of patients in order to retain patients as consumers, they are feeling pressured to provide more services with less time. According to RAND Health, the nation's largest independent health policy research program, physicians report that this, in turn, limits the amount of time they can spend with an individual patient. In some cases, this detracted from the quality of care. With less time to talk with patients, diagnose and treat, the quality of the care they received was impacted. When asked about work quantity and pace, only 60\% of physicians (mixed group of primary care physicians and specialists) responded that they "Agree" or "Strongly Agree" that they have adequate time to spend with their patients during office visits. This limited time doesn't affect just the patient. Previous studies indicate that greater time pressures to conduct clinical activities were associated with lower physician job satisfaction [9]. In 2004, the Society of General Internal Medi- 
cine (SGIM) Task Force published a report recommending that barriers which keep physicians from spending adequate time with patients need to be removed, and physicians should provide patient-centered, comprehensive, longitudinal care and be committed to quality outcomes and preventive care [10]. The SGIM Task Force also recommended that the current fee-for-service reimbursement system should be abandoned in order to provide for physician services that are outside of the traditional face-to-face visits; for example, physicians could receive a patient management fee plus reimbursement for specific services [10]. The American Medical Association (AMA) has even encouraged physicians to use tools to proactively measure patient satisfaction in order to inform quality improvement efforts, help practices make staffing decisions, give physicians a competitive edge, guide improvements in patients' health, compliance and confidence in treatment, and show patients that their physicians care about their input [11]. The American Board of Internal Medicine (ABIM) also recognizes the importance of evaluating patient satisfaction and has incorporated patient satisfaction surveys into their recertification process beginning in 2014. ABIM board certified physicians will need to complete a patient survey every 5 years. The survey must include results from a minimum of 35 patients, and based upon the results, the physician must identify one measure to improve upon, a targeted performance goal and strategies to achieve the goal. The survey then needs to be repeated in order to measure and report the impact of the identified strategies [12].

MDVIP was the first company, over a decade ago, to put together a network of primary care practices and develop a new primary care model based upon patient (i.e., consumer) empowerment. Patient satisfaction is an integral part of the patient-physician relationship and the MDVIP model is based upon strengthening this relationship. In this practice model, doctors partner with patients to keep them healthy. They spend time discussing prevention and wellness, not just dealing with chronic conditions or referring out to specialists. For an annual fee that ranges from $\$ 1,500$ to $\$ 2,200$, depending on the provider, patients receive a set of noncovered services, screenings and interventions designed to identify risk, prevent events, encourage change of detrimental lifestyle habits and improve quality of life. To be able to practice in this fashion, the practice is limited to a maximum of 600 patients. Each patient receives a 90- to 120-minute annual wellness visit similar to an executive-style physical. This includes an exam, review and coaching for every patient. Follow-up visits last 30 minutes. This is in contrast to conventional practice where physicians will have over 2000 patients in the practice and only have time to focus on trying to prevent complications of disease, not the disease itself.

To compare MDVIP member satisfaction to patients utilizing the conventional healthcare model, MDVIP commissioned IPSOS, an independent, third-party market research firm to conduct an online survey with MDVIP members and a representative population of patients in the conventional healthcare system.

\section{METHODS}

IPSOS administers the online Patient Satisfaction Survey annually to current MDVIP members and the results from 2011 and 2012 are included in this analysis. All members were contacted via email or phone and invited to complete the online survey. To compare these results to patients in the conventional healthcare ( $\mathrm{CHC}$ ) system, the survey was administered to a representative population of patients in 2011 who were a balanced outgo sample based on a national representative census of 50\% males and 50\% females who were at least 30 years of age. The questionnaire was developed with the MDVIP team and validated through automated and visual checking by programming, data processing and online operation teams. It consisted of 3 key areas. The first section included 37 questions on patient satisfaction regarding physician accessibility, office visits, medical treatment, physician and staff courtesy and physician's interaction with the patient. Participants rated each parameter using a 5-point Likert Scale: extremely satisfied (5), very satisfied (4), somewhat satisfied (3), not very satisfied (2), and not at all satisfied (1). The second area measured the patients' importance of these attributes when evaluating their overall healthcare experience using the same 5-point Likert scale assessing "importance" instead of "satisfaction." The third area assessed patient agreement to health/quality of life measures initiated by his/her physician using a 5-point scale: strongly agree (2), agree (1), neither agree nor disagree (0), disagree (-1), strongly disagree (-2).

Age group and sex were the only demographic variables collected, so no other demographics (e.g., race, socioeconomic status) could be evaluated. MDVIP members and CHC members were identified only by their member identification number; physician name and any other patient identifiers were removed for blinding purposes before data analysis. The MDVIP network has an average age of 66 and $40-45 \%$ of the network is in Medicare or a Medicare Advantage plan. The rest are covered by various commercial insurance plans. The practices mirror the demographics of the practice before transition to this model. Affiliated physicians are in 42 states and the District of Columbia and have patients from urban, suburban and rural areas.

All analyses were performed using Quantum - Version 5.8 for data processing. A standard t-test on proportions and means was calculated for each question. Percentages reported reflect the top 2 box responses (i.e., extremely satisfied and very satisfied; strongly agree and agree) for each question, unless stated otherwise.

\section{RESULTS}

A total of 13,092 MDVIP members completed the survey in 2011, 16,271 members completed the survey in 2012 and 1067 conventional healthcare patients were recruited to complete the survey in 2011. However, it was discovered that only 900 conventional healthcare patients had a primary care physician and thus were able to complete the survey. Overall, the response rate for the MDVIP members in 2011 and 2012 was $13 \%$ and $12 \%$, respectively. Table 1 shows the patient characteristics (gender and age group) that were collected by self-report. There were no significant differences between the MDVIP groups and the CHC group within each age division breakout; however, there was a significant difference in the overall average age of the CHC group compared to the MDVIP 2011 and MDVIP 2012 groups $(\mathrm{p}<0.05)$. The average age in the CHC group $(53.52 \pm 14.2)$ 
Table 1. Study population age and gender demographics.

\begin{tabular}{|c|c|c|c|}
\hline Age and Gender & $\begin{array}{c}\text { MDVIP } \\
2011 \\
a \\
(\mathbf{N}=\mathbf{1 3 , 0 9 2})\end{array}$ & $\begin{array}{c}\text { MDVIP } \\
2012 \\
b \\
(\mathrm{~N}=\mathbf{1 6 , 2 7 1})\end{array}$ & $\begin{array}{c}\text { CHC } \\
2011 \\
c \\
(\mathbf{N}=1067)\end{array}$ \\
\hline \multirow{2}{*}{$\begin{array}{c}\text { Gender } \\
\text { Male } \\
\text { Female }\end{array}$} & & & \\
\hline & $49 \%(\mathrm{~N}=6362)$ & $47 \%(\mathrm{~N}=7625)$ & $50 \%(\mathrm{~N}=534)$ \\
\hline \multicolumn{4}{|l|}{ Age Group (years) } \\
\hline $18-24$ & $<1 \%(\mathrm{~N}=9)$ & $<1 \%(\mathrm{~N}=5)$ & $0 \%(\mathrm{~N}=0)$ \\
\hline $25-34$ & $1 \%(\mathrm{~N}=95)$ & $<1 \%(\mathrm{~N}=67)$ & $10 \%(\mathrm{~N}=102)$ \\
\hline $35-44$ & $4 \%(\mathrm{~N}=527)$ & $2 \%(\mathrm{~N}=324)$ & $23 \%(\mathrm{~N}=241)$ \\
\hline 65 or over & $48 \%(\mathrm{~N}=6308)$ & $60 \%(\mathrm{~N}=9750)$ & $28 \%(\mathrm{~N}=297)$ \\
\hline Average Age (SD)* & $\begin{array}{c}63.81(11.06) \\
\mathrm{c}\end{array}$ & $\begin{array}{c}66.53(10.47) \\
\mathrm{c}\end{array}$ & $\begin{array}{c}53.52(14.2) \\
\mathrm{c}\end{array}$ \\
\hline
\end{tabular}

* Letter designations $(\mathrm{a}, \mathrm{b}, \mathrm{c})$ after the average age denote statistical significance $(\mathrm{p}<0.05)$ versus the identified group.

was approximately 10 years younger compared to the MDVIP 2011 group $(63.81 \pm 11.06)$ and the MDVIP 2012 group $(66.53 \pm 10.47)$.

\section{Important Attributes}

The most important attributes to patients based on the top box response percentages were generally consistent across all patient test groups and mainly involved the physician-patient interaction and medical treatment. Attributes that were most important to patients included physician's explanation of the patient's condition and medications, physician's ability to ask questions in order to understand the patient's condition, physician's response to questions and concerns, physician's personal interest in the patient and his/her health, physician's familiarity with the patient's medical history and staff/physician returns calls in a timely manner. Other areas of importance included the ability to get an appointment when needed, the professionalism and courtesy of the office staff, physician's responsiveness to emergencies and the follow-up plan the physician develops for the patient. Table 2 lists the top attributes of importance to patients.

\section{SATISFACTION}

\section{Physician Availability}

Patients in the MDVIP model (i.e., MDVIP 2011 and MDVIP 2012) were significantly more satisfied versus their CHC counterparts with their ability to contact their physician during business hours (90\% MDVIP 2011, 91\% MDVIP 2012, 53\% CHC patients), contact their physician after business hours (71\% MDVIP 2011, 74\% MDVIP 2012, 31\% CHC patients) and obtain an appointment within 48 hours (85\% MDVIP 2011, 87\% MDVIP 2012, 55\% CHC patients), $\mathrm{p}<0.05$ for all parameters. A significantly higher number of MDVIP members were satisfied with their ability to get an appointment when needed compared to the $\mathrm{CHC}$ patients (93\% MDVIP 2011, 94\% MDVIP 2012, 65\% CHC, p<0.05). Once in the physician's office, more patients in the MDVIP groups versus the $\mathrm{CHC}$ group claimed to wait less than 10 minutes in the reception area (78\% MDVIP 2011, 79\% MDVIP 2012, 41\% CHC patients, $\mathrm{p}<0.05)$ and overall, MDVIP members were much more satisfied with the amount of wait time they experienced in the doctor's office (94\% MDVIP 2011, 95\% MDVIP 2012, 52\% CHC, p<0.05) (Table 3).

\section{Patient-Physician Relationship}

Overall, 97\% of MDVIP members were satisfied with their relationship with their physician compared to just $58 \%$ of CHC patients $(\mathrm{p}<0.05)$. MDVIP members were statistically significantly more satisfied with their physician's attention to what they had to say, explanation of their condition and the amount of time spent with them during their appointment compared to CHC patients (see Table $\mathbf{3}$ ).

\section{Loyalty to Physician}

Patient-reported physician loyalty was much higher in both MDVIP groups compared to the CHC population. Sixty-eight percent of patients in the MDVIP 2011 group and $72 \%$ of patients in the MDVIP 2012 group reported that they would never leave their physician compared to just $44 \%$ of patients in the CHC group $(\mathrm{p}<0.05)$. Almost all of the patients in both MDVIP groups reported that they feel they are receiving the best care (92\% MDVIP 2011, 94\% MDVIP 2012 ) versus only $68 \%$ of CHC patients $(p<0.05)$, and a significantly higher number of patients in both MDVIP groups report that they feel more confident in their doctor's approach to their healthcare (79\% MDVIP 2011, 80\% MDVIP 
Table 2. Patient results - most important physician practice attributes*.

\begin{tabular}{|c|c|c|c|}
\hline Attribute & $\begin{array}{c}\text { MDVIP } 2011 \\
\text { a }\end{array}$ & $\begin{array}{c}\text { MDVIP } 2012 \\
\text { b }\end{array}$ & $\begin{array}{c}\mathrm{CHC} \\
\mathrm{c}\end{array}$ \\
\hline \multicolumn{4}{|l|}{ Physician Accessibility } \\
\hline Ability to Get an Appointment When You Need It & $98 \mathrm{c}$ & $98 \mathrm{c}$ & 91 \\
\hline Ability to Contact Your Physician During Business Hours & $94 \mathrm{c}$ & $94 \mathrm{c}$ & 75 \\
\hline \multicolumn{4}{|l|}{ Physician-Patient Interaction } \\
\hline Physician's Explanation of Your Condition(s) & $99 \mathrm{c}$ & $99 \mathrm{c}$ & 94 \\
\hline Physician's Explanation of Your Medications (Prescription and Over-the-Counter) & $97 \mathrm{c}$ & $97 \mathrm{c}$ & 89 \\
\hline Physician's Bedside Manner & $94 \mathrm{c}$ & $92 \mathrm{c}$ & 84 \\
\hline Physician's Responses to Your Questions and Concerns & $100 \mathrm{c}$ & $100 \mathrm{c}$ & 95 \\
\hline Physician's Asks Questions to Understand Your Condition & $99 \mathrm{c}$ & $99 \mathrm{c}$ & 93 \\
\hline \multicolumn{4}{|l|}{ Physician Treatment } \\
\hline Administering Your Annual MDVIP Wellness Exam and Following Up on It & $93 \mathrm{c}$ & $92 \mathrm{c}$ & 80 \\
\hline Delivering Personalized Health Care & $98 \mathrm{c}$ & $98 \mathrm{c}$ & 88 \\
\hline Physician's Personal Interest in You and Your Health & $99 \mathrm{c}$ & $99 \mathrm{c}$ & 90 \\
\hline Physician's Coordination of Your Specialist Care & $93 \mathrm{c}$ & $91 \mathrm{c}$ & 81 \\
\hline Physician's Proactive Approach to Wellness and Disease Prevention & $97 \mathrm{c}$ & $96 \mathrm{c}$ & 86 \\
\hline Diagnosing/Treating Any Problem & $99 \mathrm{c}$ & $99 \mathrm{c}$ & 95 \\
\hline \multicolumn{4}{|l|}{ Office Staff } \\
\hline Professionalism and Courtesy of Your Physician's Staff & $94 \mathrm{c}$ & $95 \mathrm{c}$ & 85 \\
\hline Nurses/Medical Assistants Are Knowledgeable & $95 \mathrm{c}$ & $95 \mathrm{c}$ & 87 \\
\hline
\end{tabular}

*Results reported as a percentage of top 2 box responses ("Extremely Important" and "Very Important"). Letter designations after the number percentage denote statistical significance $(\mathrm{p}<0.05)$ versus the identified group.

2012, 61\% CHC, $\mathrm{p}<0.05)$. Finally, significantly more MDVIP members have recommended their doctor in the past and are more likely to do so in the future. See Fig. (1).

\section{Quality of Life}

Table 4 shows patient perceptions regarding their personal health. MDVIP had a significant impact on members' perceived health. Fifty-one percent of MDVIP 2011 members and 55\% of MDVIP 2012 members believed that their health had improved since joining their doctor's practice compared to $46 \%$ of CHC patients $(p<0.05)$, and a significantly higher percentage of MDVIP members believed that they were in control of their life and their health than those in the CHC group. Interestingly, MDVIP members reported that they were more likely to eat healthy and exercise compared to their CHC counterparts (84\% MDVIP 2011, 85\% MDVIP 2012, 66\% CHC, p<0.05).

\section{DISCUSSION}

Anderson reported that the combination of long wait time and short time with the physician tends to result in the lowest levels of patient satisfaction, overall [14]. In our study, the MDVIP patients were significantly more satisfied with both of these parameters compared to the $\mathrm{CHC}$ group. 
Table 3. Patient satisfaction*. average rating (SD) and percentage of top 2 box responses -"Extremely" and "Very Satisfied" responses.

\begin{tabular}{|c|c|c|c|c|}
\hline Questions & $\begin{array}{c}\text { MDVIP } 2011 \\
\text { a } \\
\text { N=13,092 }\end{array}$ & $\begin{array}{c}\text { MDVIP } 2012 \\
\text { b } \\
\mathrm{N}=\mathbf{1 6 , 2 7 1}\end{array}$ & $\begin{array}{l}\text { Conventional Health } \\
\text { Care (CHC) c } \\
\text { N=900 }\end{array}$ & $\begin{array}{c}\text { Delta of Superiority } \\
\text { (CHC vs. MDVIP } \\
\text { 2011) }\end{array}$ \\
\hline \multicolumn{5}{|l|}{ Patient-Centered Care } \\
\hline Delivering Personalized Health Care & $\begin{array}{l}4.75(0.53) \\
95 \% \mathrm{c}\end{array}$ & $\begin{array}{l}4.77(0.52) \\
96 \% \mathrm{c}\end{array}$ & $\begin{array}{l}3.91(0.94) \\
69 \%\end{array}$ & $26 \% \mathrm{c}$ \\
\hline Relationship With Physician & $\begin{array}{l}4.79(0.49) \\
97 \% \mathrm{c}\end{array}$ & $\begin{array}{l}4.81(0.48) \\
97 \% \mathrm{c}\end{array}$ & $\begin{array}{c}3.91(0.9) \\
58 \%\end{array}$ & $39 \% \mathrm{c}$ \\
\hline $\begin{array}{l}\text { Administering Annual Wellness Exam/Physical } \\
\text { and Following Up on It. }\end{array}$ & $\begin{array}{c}4.71(0.6) \\
90 \% \mathrm{c}\end{array}$ & $\begin{array}{l}4.75(0.55) \\
90 \% \mathrm{c}\end{array}$ & $\begin{array}{l}3.92(0.95) \\
67 \%\end{array}$ & $23 \% \mathrm{c}$ \\
\hline \multicolumn{5}{|l|}{$\begin{array}{c}\text { Remove Barriers That Keep Physician From } \\
\text { Spending Time With Patients }\end{array}$} \\
\hline $\begin{array}{c}\text { Amount of Time Your Physician Spends with } \\
\text { You During Your Appointment }\end{array}$ & $\begin{array}{l}4.84(0.42) \\
97 \% \mathrm{c}\end{array}$ & $\begin{array}{l}4.84(0.42) \\
98 \% \mathrm{c}\end{array}$ & $\begin{array}{c}3.95(0.96) \\
71 \%\end{array}$ & $26 \% \mathrm{c}$ \\
\hline $\begin{array}{c}\text { Ability To Contact Physician During Business } \\
\text { Hours }\end{array}$ & $\begin{array}{l}4.69(0.6) \\
90 \% \mathrm{c}\end{array}$ & $\begin{array}{l}4.71(0.58) \\
91 \% \mathrm{c}\end{array}$ & $\begin{array}{c}3.57(1.05) \\
53 \%\end{array}$ & $37 \% \mathrm{c}$ \\
\hline Ability to Contact Physician After Business Hours & $\begin{array}{l}4.72(0.58) \\
71 \% \mathrm{c}\end{array}$ & $\begin{array}{l}4.73(0.57) \\
74 \% \mathrm{c}\end{array}$ & $\begin{array}{c}3.25(1.2) \\
31 \%\end{array}$ & $40 \% \mathrm{c}$ \\
\hline \multicolumn{5}{|l|}{ Attentiveness and Courtesy } \\
\hline $\begin{array}{l}\text { Physician's Attention to What } \\
\text { You Have to Say }\end{array}$ & $\begin{array}{c}4.83(0.46) \\
97 \% \mathrm{c}\end{array}$ & $\begin{array}{c}4.83(0.45) \\
98 \% \mathrm{c}\end{array}$ & $\begin{array}{c}4.1(0.93) \\
77 \%\end{array}$ & $20 \% \mathrm{c}$ \\
\hline $\begin{array}{l}\text { Physician's Responses to Your } \\
\text { Questions and Concerns }\end{array}$ & $\begin{array}{l}4.81(0.47) \\
97 \% \mathrm{c}\end{array}$ & $\begin{array}{c}4.82(0.46) \\
97 \% \mathrm{c}\end{array}$ & $\begin{array}{c}4.1(0.9) \\
76 \%\end{array}$ & $21 \% \mathrm{c}$ \\
\hline $\begin{array}{c}\text { Professionalism and Courtesy of Your Physician's } \\
\text { Staff }\end{array}$ & $\begin{array}{c}4.67(0.6) \\
95 \% \mathrm{c}\end{array}$ & $\begin{array}{l}4.71(0.56) \\
96 \% \mathrm{c}\end{array}$ & $\begin{array}{l}4.02(0.87) \\
75 \%\end{array}$ & $20 \% \mathrm{c}$ \\
\hline \multicolumn{5}{|l|}{ Prescribed Treatments } \\
\hline Physician's Explanation of Your Medications & $\begin{array}{c}4.78(0.49) \\
95 \% \mathrm{c}\end{array}$ & $\begin{array}{l}4.79(0.48) \\
96 \% \mathrm{c}\end{array}$ & $\begin{array}{l}4.03(0.87) \\
73 \%\end{array}$ & $22 \% \mathrm{c}$ \\
\hline Physician's Explanation of Your Condition & $\begin{array}{l}4.81(0.46) \\
97 \% \mathrm{c}\end{array}$ & $\begin{array}{l}4.81(0.46) \\
97 \% \mathrm{c}\end{array}$ & $\begin{array}{c}4.05(0.92) \\
74 \%\end{array}$ & $23 \% \mathrm{c}$ \\
\hline
\end{tabular}

* Letter designations after the number percentage denote statistical significance $(\mathrm{p}<0.05)$ versus the identified group.

In addition, a significantly higher number of MDVIP patients believe they are receiving the best care, report they would never leave their doctor and would recommend their doctor to others in the future compared to the $\mathrm{CHC}$ patients.
In a previously conducted observational study involving 60 office visits in the conventional healthcare setting, only a little over a half of the patients $(59 \%)$ said that they were satisfied with their visit. The remainder had issues related to 


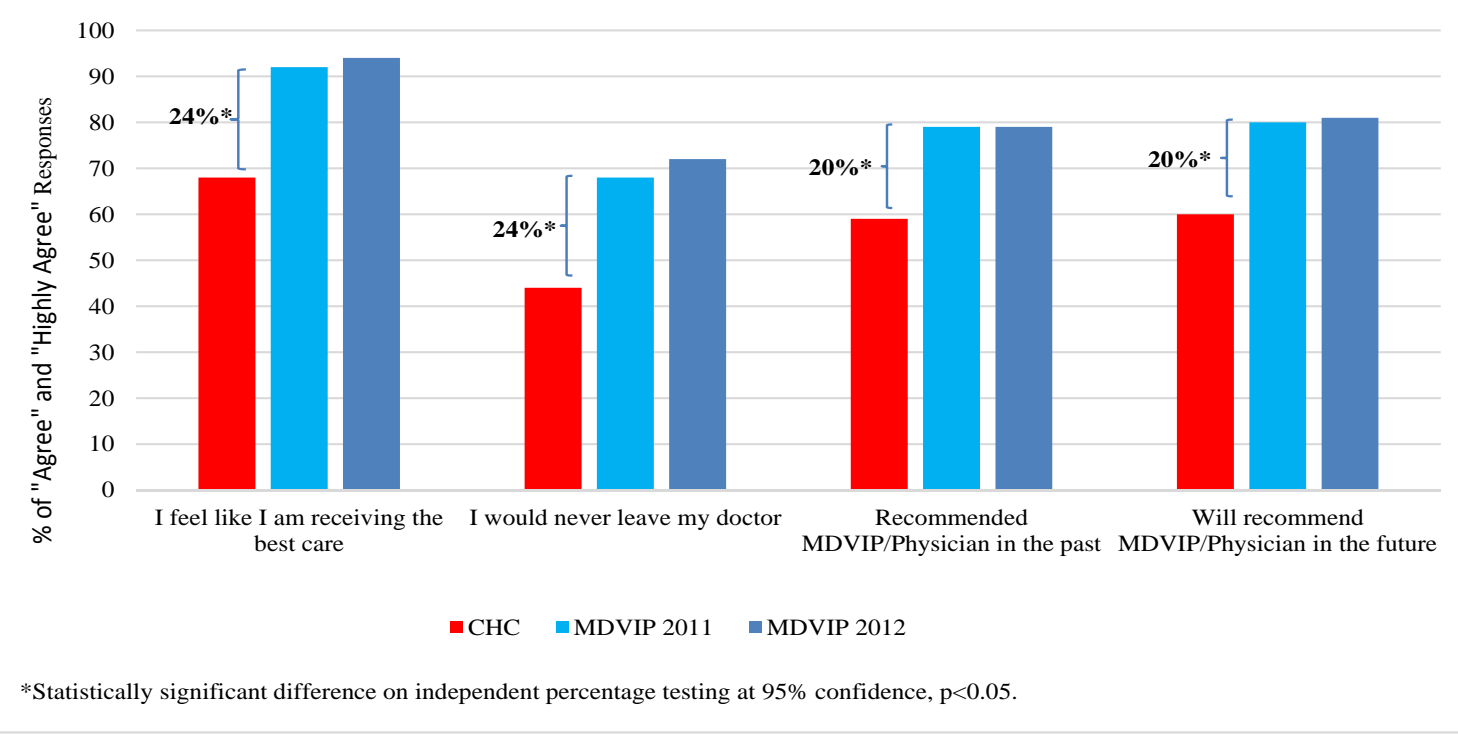

Fig (1). Patient loyalty to physician (agree and highly agree responses).

Table 4. Patient-perceived health outcomes*. Percentage of top 2 box responses - "Highly Agree" \& "Agree" responses.

\begin{tabular}{|c|c|c|c|c|}
\hline Health Parameter & $\begin{array}{l}\text { MDVIP } 2011 \text { (a) } \\
\qquad \mathrm{N}=13,092\end{array}$ & $\begin{array}{l}\text { MDVIP } 2012 \text { (b) } \\
\quad \mathrm{N}=16,271\end{array}$ & $\begin{array}{c}\text { Conventional } \\
\text { Health Care (c) } \\
\mathbf{N}=900\end{array}$ & $\begin{array}{c}\text { Delta of Superiority } \\
\text { (CHC vs. MDVIP } \\
\text { 2011) }\end{array}$ \\
\hline $\begin{array}{l}\text { I feel my condition is well managed or under control } \\
\text { since joining my doctor's practice }\end{array}$ & $74 \% \mathrm{c}$ & $77 \%$ ac & $62 \%$ & $12 \% \mathrm{c}$ \\
\hline $\begin{array}{l}\text { I feel I have an excellent quality of life for a longer } \\
\text { period of time }\end{array}$ & $69 \% \mathrm{c}$ & $74 \%$ ac & $59 \%$ & $10 \% \mathrm{c}$ \\
\hline MDVIP/my doctor helps me live a healthy, vibrant life & $56 \% \mathrm{c}$ & $62 \%$ ac & $51 \%$ & $5 \% \mathrm{c}$ \\
\hline I feel in control of my life and health & $80 \% \mathrm{c}$ & $82 \%$ ac & $73 \%$ & $7 \% \mathrm{c}$ \\
\hline $\begin{array}{c}\text { MDVIP/My Doctor plays a positive role in my } \\
\text { everyday life. }\end{array}$ & $52 \% \mathrm{c}$ & $58 \%$ ac & $47 \%$ & $5 \% \mathrm{c}$ \\
\hline
\end{tabular}

*Letter designations after the number percentage denote statistical significance $(\mathrm{p}<0.05)$ versus the identified group.

the service they had received including time spent waiting in both the reception area and examination room, with an average wait time of 31 minutes. The amount of time that the physician actually spent with the patient also impacted the degree of satisfaction. Patients reported that the physicianpatient relationship $(45 \%)$ and the medical information received $(41 \%)$ were the most valued parts of the visit [15]. This is consistent with other studies that indicated that the patient's most important attributes of healthcare are patientcentered, including time spent with the physician, the willingness of the physician to listen to the patient and expectations for treatment [14].
The MDVIP personalized preventive care model is an innovative and important model due to the high and everincreasing costs of U.S. healthcare and the shift to consumer empowerment. The Medical Outcomes Study of over 17,000 patients showed that it was desirable for providers to reduce patients' office waits and spend more time with patients [16]. Notably, the authors concluded that even though these improvements might decrease revenues, it was important to find the most cost-effective ways to improve patients' experiences. Thus, MDVIP was the first company to develop this new model that focuses on personalized preventive healthcare by delivering preventive screenings and diagnos- 
tics as well as limiting the number of members in each practice to be able to logistically deliver the service. The model design allows physicians to provide more personalized attention to disease screening and prevention programs, not just the diagnosis and treatment of illness [17]. An annual membership fee pays for the preventive and wellness services not covered by managed care or other common health insurance plans and enables physicians to decrease their practice size. The physician now has the time to spend with patients during their yearly wellness exam (90-120 minutes) and for routine follow-up visits (30 minutes). As a result, MDVIP members receive same-day or next-day appointments for urgent and non-urgent care and the ability to reach their physician 24 hours a day [17]. However, this model is not a third-party payer; members still need traditional health insurance to cover the costs of inpatient and outpatient visits, services provided by specialists and other medical services (e.g., labs, $\mathrm{X}$-rays) [17]. Since they are paying an annual membership fee in addition to their insurance premiums, MDVIP members may have a greater expectation of service; nevertheless, results from this survey show that the majority of MDVIP members are having their expectations met or exceeded, would continue/renew their membership and would recommend MDVIP to family and friends.

Interest in determining patient satisfaction/experiences with regard to physician interactions has been increasing in recent years primarily because patients are more involved in decisions and assuming more costs of their healthcare. The Patient Protection and Affordable Care Act of 2010 mandated that the Centers for Medicare and Medicaid Services (CMS) utilize the Consumer Assessment of Healthcare Providers and Systems (CAHPS) surveys developed at the Agency for Healthcare Research and Quality (AHRQ) for public reporting. [18]. It is currently the most widely used survey instrument that asks consumers about their experiences with and evaluations of ambulatory care received from both health plans and healthcare professionals. The CAHPS 2.0 questionnaire, which includes 43 questions regarding access to care, doctor communication, office staff, getting needed care and health plan customer service, is conducted by mail or telephone and distributed to members of privately insured health plans serving public and private employers (including Medicare beneficiaries) across the U.S. Data from the CAHPS surveys are publically available and are used by a wide range of health plans, including state Medicaid programs, employer groups, the Medicare program and the Federal Employees Health Benefits Program [19].

In the first 12-month, national Clinician and Group (C\&G) Survey report compiled and released by the CAHPS Database in November 2010 of 128,030 adult responders, the highest scoring CAHPS composite was doctor communication, and the lowest scoring composite was access to care across all physician specialties [19]. The results seen in our $\mathrm{CHC}$ population were very consistent with the findings from the $C \& G$ survey (Adult Primary Care 6-point scale version). In the C\&G survey, $62 \%$ of respondents stated that they "always" ("top box score" on 6-point scale) received an appointment for care as soon as they thought they needed it, compared with $65 \%$ of $\mathrm{CHC}$ patients in our study. With respect to the ability to contact the doctor's office about a medical question, $55 \%$ of $C \& G$ survey responders stated that they "always" could get answers during business hours, and $64 \%$ stated that they "always" could get answers after regular office hours. Again, these results were similar to what we found in the CHC population who reported that $53 \%$ could contact their physician during business hours and only $31 \%$ could contact their physician after business hours. In the C\&G survey, $27 \%$ of responders stated that their office visit "always" started within 15 minutes of the appointment time, compared to $41 \%$ of the $\mathrm{CHC}$ population reporting that their average time in the waiting room was less than 10 minutes. Finally, when participants were asked about doctor communication, $74 \%$ of $C \& G$ survey responders stated that the doctor "always" spends enough time with them compared to $71 \%$ of the $\mathrm{CHC}$ group, and $78 \%$ of $\mathrm{C} \& \mathrm{G}$ survey responders stated that their doctor "always" explains things in a way that is easy to understand versus 74\% of CHC responders [19].

As expected, MDVIP members reported higher "top box" responses regarding access to care and doctor communication compared to the national $\mathrm{C} \& \mathrm{G}$ survey for all comparable questions. Overall, when compared to both the $C \& G$ survey results and the $\mathrm{CHC}$ group results, the majority of the parameters evaluated were rated significantly higher by MDVIP members.

The results of this patient satisfaction survey are not just important from an emotional standpoint. Several studies have reported that good physician-patient communication can promote patient adherence with their prescribed treatment plan and ultimately improve health outcomes, patient feelings about their disease and the impact on their life [18, $20,21]$. In one study of patients who were being treated for acute myocardial infarction (AMI), those patients who reported better patient care had significantly better survival rates one year post AMI. In another study looking at patient satisfaction in hospitals, the hospitals with higher patient satisfaction ratings were associated with lower in-hospital complications and patient mortality [18]. Conversely, health status and health outcomes affect satisfaction. In general, sicker patients tend to report lower satisfaction, with the possible exception of some chronically ill groups [22]. Our study supports these findings. The MDVIP population reported higher satisfaction with their physician relationship than patients in the conventional healthcare group and also tended to eat healthier and exercise more.

The 2013 MDVIP member satisfaction survey has just been completed and topline results show that patient satisfaction continues to be strong with $92 \%$ of members very/extremely satisfied with being a patient in an MDVIPaffiliated practice, which is statistically higher than prior years. Overall, member experience satisfaction continues to be high and there was a strong intention for patients to renew their membership (90\%). This is consistent with yearly renewal rates of $92-94 \%$ over this time period.

The results from this survey demonstrated that the majority of MDVIP members are satisfied with the quality of care they receive. In addition to being a personalized preventive model that is patient-centered, MDVIP believes that the additional attention, time and focus on prevention and wellness will lead to better health outcomes and ultimately lower healthcare costs. In MDVIP's first comparative utilization study of commercial and Medicare health plans from the 
Intellimed database, MDVIP commercially insured members were approximately $72 \%$ less likely to be hospitalized and MDVIP Medicare members were $79 \%$ less likely to be hospitalized relative to nonmembers in 2010 [23]. This reduction in hospitalizations represents a monetary savings of $\$ 2,551$ per patient and over $\$ 300$ million to the Medicare program annually. The cost savings in hospital utilization alone would more than cover the MDVIP annual membership fee and would ensure that patients get comprehensive, integrated care. A second study also showed significantly fewer hospitalizations and ER admissions in the MDVIP Medicare Advantage population [13].

There are several limitations to this study. The patients in the MDVIP groups were, on average, approximately 10 years older compared to the CHC group (approximately 65 years of age versus approximately 55 years of age) and overall, all 3 study groups were older populations, so the results presented here may not necessarily be generalizable to other settings or groups of patients. Interestingly, the $\mathrm{CHC}$ results were similar to other data published in the literature for older patients. Also, only a small amount of demographic information was collected since this portion of the satisfaction survey was optional, so it is difficult to determine how our results are impacted by race, socioeconomic factors, etc. In addition, for some questions (e.g., your physician's responsiveness to emergencies, your physician's care when you are hospitalized), the number of responders was lower; however, these questions were not necessarily applicable to all responders, and therefore the answer was missing (i.e., not applicable).

\section{CONCLUSION}

In conclusion, the MDVIP model may enable a better primary care physician-patient relationship versus the conventional healthcare system, which could ultimately result in improved health outcomes. Today's healthcare system does not provide the patient convenience that is seen in the MDVIP model. Patients in the MDVIP model have better access to their physician, both during and after business hours, tend to be more satisfied with their ability to get an appointment when they need it and have a shorter wait time once they reach the office. MDVIP members demonstrated significantly greater loyalty to their physician by reporting that they would never leave him/her and are more likely to recommend their doctor to others. Finally, the MDVIP model appears to have a positive, significant impact on members' self-perceived health, with more members believing that their health has improved since joining their doctor's practice, and empowering members to believe that they are in control of their life and their health.

\section{CONFLICT OF INTEREST}

Andrea Klemes is an officer at MDVIP. Harold Solomon is an MDVIP-affiliated physician.

\section{ACKNOWLEDGEMENTS}

The authors gratefully acknowledge the assistance of Robin Spletzer in the writing and preparation of the manuscript and IPSOS and Monica Edelman for data consultation.

\section{APPENDIX 1}

\section{Patient Satisfaction Survey Questions}

1. Delivering personalized health care

2. Physician's personal interest in you and your health

3. Familiar with your medical history

4. Relationship with physician

5. Administering annual wellness exam/physical and following up on it

6. Physician's proactive approach to wellness and disease prevention

7. The follow-up plan your doctor develops for your health

8. Physician's coordination of your specialist care

9. Physician's approach to wellness and prevention

10. The amount of time your physician spends with you during your appointment

11. Ability to contact physician during business hours

12. Ability to contact physician after business hours

13. Your physician's responsiveness to emergencies

14. I feel better equipped to navigate the complex healthcare system

15. Ability to get an appointment when you need it

16. Ability to get a same-day appointment

17. Has office hours on evenings/Saturdays

18. Convenience of office location

19. Amount of time you wait in the waiting room

20. Amount of time you wait in exam room before seeing doctor

21.Physician's attention to what you have to say

22. Physician's responses to your questions and concerns

23. Physician asks questions to understand your condition

24. Staff/Doctor returns calls in a timely manner

25. Nurses/Medical Assistants are knowledgeable

26. Professionalism and courtesy of your physician's staff

27. Reception area helps you feel at ease

28. Examination room is pleasant

29. Diagnosing/treating any problem

30. Physician's follow-up call to deliver test/imaging results

31. Physician's ability to make you /family confident in self-care management after visit

32. Physician's follow-up after hospitalization

33. Physician's explanation of your medications

34. Physician's explanation of your condition

35 . Your physician's bedside manner

36. Being a patient in an MDVIP practice

37. Goes extra mile for you despite insurance barriers 


\section{REFERENCES}

[1] Baron RJ. What's keeping us so busy in primary care? A snapshot from one practice. N Engl J Med 2010; 362:1632-6.

[2] Showstack J, Lurie N, Larson EB, Rothman AA, Hassmiller S. Primary care: the next renaissance. Ann Intern Med 2003; 138(3): 268-72.

[3] Ginsburg PB. Payment and the future of primary care. Ann Intern Med 2003; 138(3): 233-4.

[4] Black N, Jenkinson C. How can patients' views of their care enhance quality improvement? BMJ 2009; 339: b2495.

[5] Linz AJ, Haas PF, Fallon Jr. F, Metz RJ. Impact of concierge care on healthcare and clinical practice. J Am Osteopath Assoc 2005; 105: 515-20.

[6] Dowd BE, Kralewski JE, Kaissi AA, Irrgang SJ. Is patient satisfaction influenced by the intensity of medical resource use by their physicians? Am J Manag Care 2009; 15(5): e16-21.

[7] Fan VS, Burman M, McDonell MB, Fihn SD. Continuity of care and other determinants of patient satisfaction with primary care. $\mathbf{J}$ Gen Intern Med 2005; 20: 226-33.

[8] Saultz JW, Albedaiwi W. Interpersonal continuity of care and patient satisfaction: a critical review. Ann Fam Med 2004; 2: 44551.

[9] Friedberg MW, Chen PG, Van Busum KR, et al. Factors affecting physician professional satisfaction and their implications for patient care, health systems, and health policy. Available at http://www.rand.org/pubs/research_reports/RR439.html. [Accessed 3/5/2014].

[10] Larson EB, Fihn SD, Kirk LM, et al. The future of general internal medicine: report and recommendations from the Society of General Internal Medicine (SGIM) Task Force on the domain of general internal medicine. J Gen Intern Med 2004; 19: 69-77.

[11] American Medical Association website. Available at http://www.ama-assn.org/ama/pub/advocacy/current-topicsadvocacy/private-sector-advocacy/patient-experience-surveytool.page. [Accessed 4/15/2014].

[12] American Board of Internal Medicine website. Available at http://www.abim.org/maintenance-of-certification/requirements/ patient-safety-patient-survey.aspx. [Accessed 5/26/2014].
[13] Musich S, Klemes A, Kubica M, Wang S, Hawkins K. Personalized preventive care reduces healthcare expenditures among Medicare Advantage beneficiaries. Am J Manag Care 2014; 20: 613-20.

[14] Anderson RT, Camacho FT, Balkrishnan R. Willing to wait?: The influence of patient wait time on satisfaction with primary care. BMC Health Serv Res 2007; 7: 31. doi:10.1186/1472-6963-7-31.

[15] Rhoades DR, McFarland KF, Holmes Finch W, Johnson AO Speaking and interruptions during primary care office visits. Fam Med 2001; 33(7): 528-32.

[16] Rubin HR, Gandek B, Rogers WH, et al. Patients' ratings of outpatient visits in different practice settings. Results from the medical outcomes study. JAMA 1993; 270(7): 8358-40.

[17] French MT, Homer JF, Klevay S, Goldman E, Ullmann SG, Kahn BE. Is the United States ready to embrace concierge medicine? Popul Health Manag 2010; 13(4); 177-82.

[18] Anhang Price R, Eliott MN, Zaslavsky AM, et al. Examining the role of patient experience surveys in measuring health care quality. Med Care Res Rev [published online 15 Jul 2014]. doi:10.1177/1077558714541480.

[19] The CAHPS Database. Preliminary comparative data for the CAHPS clinician and group survey (12-month version). November 2010. Available at https://cahps.ahrq.gov/quality-improvement/ improvement-guide/analysis-of-results/Analyze-CAHPS-Data/ Compare_CAHPS-Scores Benchmarks/ClinicianGroupPreliminary Report11_2010.pdf. [Accessed 5/27/2014].

[20] Stewart MA. Effective physician-patient communication and health outcomes: a review. Can Med Assoc 1995; 152: 1423-33.

[21] Kaplan SH, Greenfield S, Ware Jr JE. Assessing the effects of physician-patient interactions on the outcomes of chronic disease. Med Care 1989; 27: S110-S27.

[22] Crow R, Gage H, Hampson S, et al. The measurement of satisfaction with healthcare: implications for practice from a systematic review of the literature. Health Technol Asses 2002; 6: 32 (Executive Summary).

[23] Klemes AB, Seligmann RE, Allen L, Kubica MA, Warth K, Kaminetsky B. Personalized preventive care leads to significant reductions in hospital utilization. Am J Manag Care 2012; 18: e453e60.

(C) Klemes and Solomon; Licensee Bentham Open.

This is an open access article licensed under the terms of the Creative Commons Attribution Non-Commercial License (http://creativecommons.org/licenses/by-nc/3.0/) which permits unrestricted, non-commercial use, distribution and reproduction in any medium, provided the work is properly cited. 